\title{
Cobrança pelo uso da água na bacia hidrográfica do rio Formoso - TO: Estudo de Viabilidade Financeira
}

\author{
Charging for water use in Formoso river basin - Tocantins state: \\ Study of financial feasibility
}

\section{Luiz Norberto Lacerda Magalhães Filho Fernán Enrique Vergara Waldecy Rodrigues}

RESUMO: O trabalho buscou analisar a viabilidade na aplicaçáo da cobrança pelo uso da água na bacia do rio Formoso, localizada no Tocantins, avaliandoa capacidade de pagamento dos usuários agrícolas (irrigantes), responsáveis por mais de $97 \%$ do consumo de água,ondese aplicou o método residual, e alcançou-se o valor de $0,0067 \mathrm{R} \$ / \mathrm{m}^{3}$ de água. Dentre os instrumentos da Política Nacional de Recursos Hídricos, alémda cobrança, está o plano de bacia, que determina as açóes e programas a serem realizados, na busca em delimitar o preço da água necessário para implantar as açóes do plano de bacia, criaram-se cenários de financiamento e observou-se a viabilidade da cobrança quando $25 \%$ dos custos para implantação dos projetos do plano de bacia vêm dos usuários, cobrando em média $0,0036 \mathrm{R} \$ / \mathrm{m}^{3}$, ou seja, metade da capacidade de pagamento do produtor agrícola, de forma que náo comprometa todo seu lucro.

PALAVRAS CHAVE: Cobrança, Capacidade de Pagamento, Viabilidade.
Submetido: 10-04-15

Revisão: 31-05-15

Aprovado: 03-07-15
ABSTRACT: The study aimed to analyze the feasibility of applying a method for water use charges in the Formoso river basin, located in the state of Tocantins, assessing the agricultural users' (irrigators) capacity to pay. These users account for over $97 \%$ of water consumption. The residual method was applied and reached the value of $0.0067 \mathrm{R} \$$ / $\mathrm{m}^{3}$ of water. Among the instruments of the National Water Resources Policy, besides charging, is the basin plan, which determines the actions and programs to be carried out to define the price of water needed to implement the actions of the basin plan. Scenarios were created for funding and the feasibility of charging when $25 \%$ of the costs for basin plan project implementation come from users, charging an average of $0.0036 \mathrm{R} \$ / \mathrm{m}^{3}$, in other words, half of the farmers' payment capacity so that all their profits will not be compromised.

KEYWORDS: Collection, Payment Capability, Feasibility.

\section{INTRODUÇÃO}

Muito se tem discutido recentemente acerca da importância da água para a manutenção da vida e das diversas atividades humanas, no que se refere a dois importantes aspectos: a mudança de paradigma quanto à gratuidade e a necessidade urgente de medidas que revertam o atual quadro de degradação (NUNES JUNIOR; MAGALHÃES JÚNIOR, 2009).

Aquino et al. (2013), destaca que essa degradação vem ocasionando a intensificaçáo da escassez quantitativa e qualitativa dos recursos hídricos, tanto na escala nacional e internacional como mostram o Plano Nacional de Recursos Hídricos (MENDONÇA, 2006) e o Human Development Report 2006.
O Brasil definiu por meio de seu marco legal a política nacional de recursos hídricos, Lei 9.433/97, que a água tem valor econômico e estabeleceu a Cobrança pelo seu uso como um dos instrumentos de gestão dos recursos hídricos.

A cobrança pelo uso da água, pressupostos que possuem raízes na experiência francesa, desponta como um valioso, porém polêmico, instrumento de gestão incumbido de promover o uso racional dos recursos hídricos e gerar recursos financeiros para os comitês de bacia hidrográfica. Polêmico devido ao seu caráter pioneiro no país, em que a carga tributária já é bem elevada e onde o conhecimento e as informaçóes nem sempre são adequadamente difundidos na sociedade. Há muitas incertezas, desconfianças e falta 
de conhecimento acerca deste instrumento (NUNES JUNIOR; MAGALHÃES JÚNIOR, 2009).

A Cobrança tem ocorrido de forma diversa no Brasil. A maneira como é operada nas bacias hidrográficas do Ceará (TEIXEIRA, 2003), por exemplo, cujo enfoque está na oferta e demanda da quantidade, é diferente da metodologia estabelecida na bacia do rio Paraíba do Sul, na região sudeste do Brasil, cujo enfoque está na qualidade da água (ANA, 2010).

As obras de infraestrutura hídrica geralmente esbarram no problema de escassez de recursos financeiros para a sua construção (AQUINO et al., 2013). A necessidade de expansão e melhoria do sistema, assim como, a construção de novas estruturas de abastecimento geralmente são financiados com recursos do tesouro Federal ou Estadual.

Uma alternativa a essas fontes de financiamento tradicionais seria a captação dos recursos para construção de infraestrutura hídrica por meio da cobrança pelo uso da água bruta. Todavia, as formas como os recursos da cobrança são aplicados devem estar presente no plano de recursos hídricos da bacia hidrográfica, portanto, existe a possibilidade de parte desses recursos serem utilizados em obras de infraestrutura hídrica da bacia.

A bacia hidrográfica do rio Formoso, situada na região sudoeste do Estado do Tocantins, possui grande importância econômica para o Estado, uma vez que nela se localizam projetos agrícolas com cultivo de arroz, feijão, milho e melancia. O principal uso da água na Bacia do rio Formoso é a irrigação, com destaque para o método de plantio de arroz por inundação. Por conta dessa utilização, existem vários conflitos, o que provoca grande pressáo sobre os recursos hídricos, devido, principalmente, à grande demanda que as atividades agrícolas apresentam. Com a implementação dos instrumentos da política de recursos hídricos percebe-se que instrumentos de controle (outorga de uso da água, por exemplo) por si só não suficientes para alcançar os objetivos da política.

A discussão do valor da água na bacia em estudo se apoia na necessidade de induzir os usuários de água a uma utilizaçáo racional desse recurso, uma vez que ao pagar por esse recurso, o usuário será estimulado a uma mudança em seu comportamento, tornando-se mais cuidadoso com seu uso. Além disso, haverá montante financeiro para financiar parte das obras hídricas previstas no plano de bacia. Com isso, este trabalho visa verificar a viabilidade financeira dos usuários para a implantação de um sistema de cobrança pelo uso da água.

\section{MATERIAL E MÉTODOS}

A precificação da água e a análise da viabilidade da aplicação desse valor na bacia do rio Formoso foi avaliada a partir da realizaçáo de cenários para a aplicação da cobrança. Para tanto, seguiu-se as seguintes etapas:

\section{Levantamento de dados}

O período de estudo corresponde aos anos de 2008 a 2012, intervalo definido por conta das outorgas de direito de uso recursos hídricos terem a validade média de cinco anos. Os dados obtidos junto ao órgão fiscalizador ambiental do Tocantins Instituto Natureza do Tocantins (NATURATINS), com esses dados foi possível caracterizar os usuários para que então se delimitasse a sua capacidade de pagamento. Informaçóes relativas aos custos para a produção agrícola foram levantados em estudos realizados pela Empresa Brasileira de Pesquisa Agropecuária (EMBRAPA). A produtividade e receitas geradas pelas atividades agrícolas na regiáo da bacia do rio Formoso foram coletadas no Instituto Brasileiro de Geografia e Estatística (IBGE).

\section{Precificação da água}

Neste trabalho, como a irrigação da cultura de arroz é a atividade que mais demanda água na área em estudo, foi realizado o cálculo da capacidade de pagamento dos usuários agrícolas irrigantes da bacia do rio Formoso. Além da alta demanda, os irrigantes são os usuários com a menor capacidade de pagamento, pois é necessária uma grande quantidade de água como insumo e o lucro por unidade produzida é baixo. Com isso, ao se definir a capacidade de pagamento dos agricultores, se estimaria um valor que todos os demais usuários poderiam pagar.

Para o cálculo da capacidade de pagamento, primeiramente deve-se ter o pressuposto de que todas as receitas e custos referem-se exclusivamente às atividades produtivas que usam água como insumo básico para irrigação. Logo, não são inclusos os ganhos de atividades extras e não irrigadas executadas pelo proprietário/empresário, como comércio, trabalho assalariado fora da propriedade, doaçóes de familiares, nem custos particulares dele ou da família ou da residência (CAMPOS, 2010). 
Calcula-se a capacidade de pagamento total (CPT) do produtor em relação a um dado fator, usando-se o método residual. Segundo Agüero (1996) e Bate; Dubourg (1997), este método permite determinar o valor do recurso hídrico por meio de análise e desagregação de orçamentos das unidades produtivas. O mesmo consiste em subtrair, da receita bruta total obtida, a remuneração de todos os fatores de produçáo empregados na(s) atividade(s), encontrando-se um resíduo que refletirá a capacidade de poupança gerada pelo produtor para fazer face ao uso da água como fator de produção. Matematicamente, tem-se a Equação 1:

$$
\mathrm{CPT}=\mathrm{RBT}-\mathrm{CT}
$$

Sendo:

CPT - Capacidade de pagamento total pelo fator água ou renda líquida residual $(\mathrm{R} \$)$;

RBT - Receita bruta total das atividades que usam a água como fator de produção (no caso, culturas irrigadas) (R\$);

CT - Custo total (fixos e variáveis), exceto o custo do fator água $(\mathrm{R} \$)$.

Partindo desse valor é possível determinar a capacidade de pagamento unitária.

\section{Capacidade de Pagamento Unitária}

A capacidade de pagamento unitária, isto é, por unidade do fator, é estimada como (Equação 2):

$$
\mathrm{CPu}=\mathrm{CPT} / \mathrm{V}
$$

Sendo:

$\mathrm{CP}_{\mathrm{u}}$ - Capacidade de pagamento unitária, em $(\mathrm{R} \$ /$ $\left.\mathrm{m}^{3}\right)$;

CPT - Capacidade de pagamento total pelo fator água $(\mathrm{R} \$)$;

$\mathrm{V}=$ Volume anual de água consumido $\left(\mathrm{m}^{3}\right)$.

A capacidade de pagamento unitária foi utilizada para determinar o valor máximo que pode ser pago pelos produtores agrícolas pelo metro cúbico de água, ou seja, o preço unitário da água.A presente metodologia de estimativa da capacidade de pagamento, embora seja de fácil aplicabilidade, possui um fator limitante, por utilizar todo o benefício líquido da atividade para o pagamento da água, não haveria retorno financeiro na atividade agrícola im- possibilitando o seu desenvolvimento, por isso foram criados cenários, conforme discutido a seguir, que aplicariam diferentes percentuais dessa capacidade de pagamento.

\section{Análise de Preço Unitário e Viabilidade Financeira da Cobrança}

Tendo a capacidade de pagamento total, criaram-se cinco cenários quanto à aplicação dos recursos para o financiamento de açóes previstas no plano de bacia do rio Formoso.

Cenários: aplicação dos recursos da cobrança no financiamento de 100, 75, 50, 25 e 10\% das açóes propostas no plano de bacia.

Da mesma forma que os cenários de aplicação dos recursos, determinaram-se outros 05 cenários de avaliação da capacidade de pagamento:

Cenários: 100, 75, 50, 25 e 10\% da capacidade de pagamento total sendo aplicada na cobrança.

Com a criação dos cenários observou-se se o custo unitário do metro cúbico de água pode ou não ser pago pelos produtores e verificado se as receitas obtidas podem financiar parte das açóes do Plano de Bacia Hidrográfica do rio Formoso e qual dos cenários seria mais próxima da viabilidade.

\section{RESULTADOS E DISCUSSÃO}

\section{Caracterização dos Usuários de Água da bacia}

A irrigação é a atividade que mais demanda água na bacia, 97\% do volume outorgado. A Figura 01 evidencia o aumento de área irrigada durante os anos de 2008 a 2012. Atualmente são mais de 77.000 ha irrigados na bacia do rio Formoso, com um aumento anual da área outorgada a partir de 2008 de $(17.038,87 \mathrm{ha})$, 2009 (18.315,76 ha), 2010 (25.631,82 ha), 2011 (14.796,68 ha) e $2012(1.248,28)$.

A vazão captada para a irrigação é de mais de 4,9 milhóes de $\mathrm{m}^{3} / \mathrm{dia}, 97 \%$ de toda a vazáo outorgada da bacia (Tabela 1). A irrigação é o principal uso na região. "A bacia do rio Formoso está inserida na área do Projeto Javaés que prevê grandes perímetros irrigados abastecidos pelo rio Formoso e seus afluentes" (RIBEIRO, 2007).

\section{Estudo Sobre a Capacidade de Pagamento dos Produtores de Arroz na bacia}

Para desenvolver o estudo sobre o a capacidade de pagamento da produçáo de arroz irrigado na Bacia 


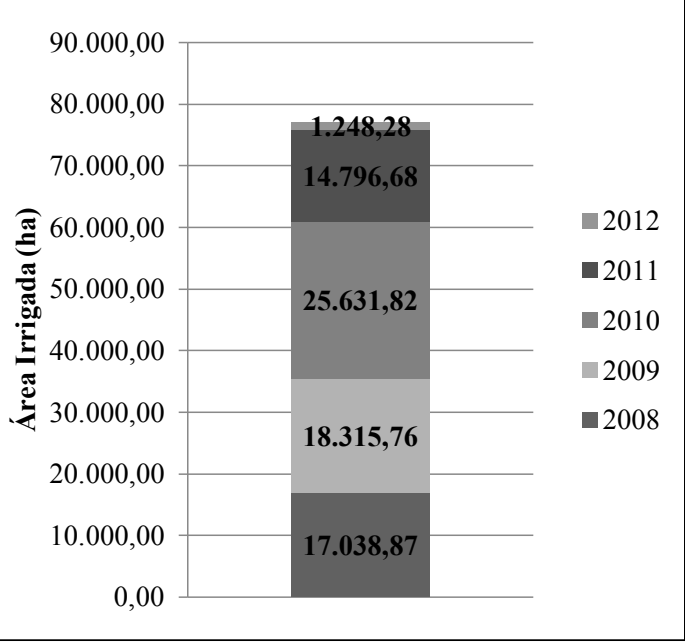

FIGURA 1. Área irrigada outorgada durante os anos de 2008-2012 na bacia do rio Formoso e total irrigado até 2012.
TABELA 1

Quantidade de outorgas e vazão dos tipos de uso da água outorgados na bacia do rio Formoso

\begin{tabular}{|l|c|c|}
\hline Tipo de Uso da Água & Q m³/dia & Percentual \\
\hline Abast. Industrial & $7.945,03$ & $0,157 \%$ \\
\hline Abast. Público & $15.492,99$ & $0,305 \%$ \\
\hline Dessedentação Animal & $18.770,74$ & $0,370 \%$ \\
\hline Irrigação & $4.925 .295,25$ & $97,045 \%$ \\
\hline Mineração & 953,20 & $0,019 \%$ \\
\hline Não Definido & $102.491,07$ & $2,019 \%$ \\
\hline Obra Hidráulica & 744,00 & $0,015 \%$ \\
\hline Piscicultura & $3.154,00$ & $0,062 \%$ \\
\hline Diluição de Efluentes & 438,80 & $0,009 \%$ \\
\hline
\end{tabular}

hidrográfica do rio Formoso, foi necessário identificar a receita total auferida com a produção e o lucro obtido. Esses dados foram coletados no período de 2008 a 2011.

Os dados referentes à receita total no período foram extraídos do Instituto Brasileiro de Geografia e Estatística (Tabela 2). A média da receita auferida que será utilizada para o cálculo da capacidade de pagamento foi o valor de $\mathrm{R} \$ 176.099 .000,00 /$ ano na bacia do rio Formoso.

TABELA 2

Receita Total referente à produção de arroz irrigado na bacia do rio Formoso

\begin{tabular}{|c|c|}
\hline Ano & Receita total (R\$) \\
\hline 2008 & $169.850 .000,00$ \\
\hline 2009 & $159.918 .000,00$ \\
\hline 2010 & $171.436 .000,00$ \\
\hline 2011 & $203.192 .000,00$ \\
\hline Média Anual & $176.099 .000,00$ \\
\hline
\end{tabular}

Fonte: IBGE (2014).

Os custos da produção de arroz irrigado por hectare foram obtidos junto à EMBRAPA, em estudo realizado no estado do Tocantins em 2004. Esse valor foi atualizado por meio do Índice Geral de Preços do Mercado (IGPm) da Fundação Getúlio Vargas (FGV) para os anos de 2008, 2009, 2010 e 2011. A média, quatro anos, apurada foi de $\mathrm{R} \$ 2.605,88 /$ ha, que multiplicado pela média da área com plantio de arroz, resultou no custo de produçáo de $\mathrm{R} \$$ 164.014.087,20 (Tabela 3).

TABELA 3

Custo de produção do arroz irrigado por hectare na bacia do Rio Formoso

\begin{tabular}{|c|c|}
\hline Ano & Preço de Custo (R\$/ha) \\
\hline 2008 & $2.456,49$ \\
\hline 2009 & $2.493,98$ \\
\hline 2010 & $2.623,16$ \\
\hline 2011 & $2.849,90$ \\
\hline Média Anual & $2.605,88$ \\
\hline
\end{tabular}

Fonte: Adaptado de EMBRAPA (2013). 
A fim de comprovar a relação entre as variáveis que foram utilizadas para a determinação da capacidade de pagamento dos usuários de água, realizou-se uma analise de correlação entre os custos de produção, área irrigada e a receita total (tabela 4).

TABELA 4

Análise de correlação das variáveis do estudo

\begin{tabular}{|l|l|c|}
\hline \multicolumn{2}{|c|}{} & Custo de Produção \\
\hline \multirow{2}{*}{$\begin{array}{l}\text { Área } \\
\text { Irrigada }\end{array}$} & Coeficiente de Pearson & 0,935 \\
\cline { 2 - 3 } & Significância & $6,5 \%$ \\
\hline \multirow{2}{*}{$\begin{array}{l}\text { Receita } \\
\text { Total }\end{array}$} & Coeficiente de Pearson & 0,927 \\
\cline { 2 - 3 } & Significância & $7,3 \%$ \\
\hline
\end{tabular}

Para a análise utilizou-se o Coeficiente de correlação de Pearson, medida do grau de relação linear entre duas variáveis quantitativas. Esse coeficiente varia entre os valores $-1,0$ e 1,0 . O valor 0 (zero) significa que não há relação linear, o valor 1,0 indica uma relação linear perfeita e o valor -1,0 também indica uma relação linear perfeita mas inversa, ou seja quando uma das variáveis aumenta a outra diminui, quanto mais próximo estiver de 1,0 ou -1,0, mais forte é a associação linear entre as duas variáveis.

Além disso, observou-se o nível de significância entre as variáveis.A significância estatística de um resultado é uma medida estimada do grau em que este resultado é "verdadeiro" representando um índice decrescente da confiabilidade de um resultado, valores próximos a $0 \%$ indicam uma confiança na relação entre as variáveis.

O Coeficiente de Pearson resultou na alta relação entre o Custo de produção com as variáveis: Área irrigada $(0,935)$ e a Receita total $(0,927)$, além disso, a significância foi abaixo de $10 \%$ para os dois casos. Com isso, baseado nessas analises pode-se concluir que as variáveis, Custo de produção e Receita total, estáo se relacionando e podem ser utilizadas para a determinaçáo da capacidade de pagamento.

Os valores utilizados para o cálculo da capacidade de pagamento são resumidos na Tabela 5 .

Com as médias da receita anual e do custo de produção do arroz, calculou-se a capacidade de pagamento total (CPT), conforme a Equação 1.

$$
\begin{aligned}
& \mathrm{CPT}=\mathrm{RBT}-\mathrm{CT} \\
& \mathrm{CPT}=\mathrm{R} \$ 176.099 .000,00-\mathrm{R} \$ 164.014 .087,20 \\
& \mathrm{CPT}=\mathrm{R} \$ 12.084 .912,80
\end{aligned}
$$

Com a capacidade de pagamento total, determinou-se a capacidade de pagamento unitária, utilizando-se além da CPT, o volume anual de água consumido.

TABELA 5

\section{Dados utilizados para o cálculo da capacidade de pagamento}

\begin{tabular}{|l|c|}
\hline \multicolumn{1}{|c|}{ Descrição } & Quantidade \\
\hline $\begin{array}{l}\text { Média anual da Área Plantada de } \\
\text { Arroz Irrigado }\end{array}$ & 62.940 hectares \\
\hline $\begin{array}{l}\text { Média anual da Produção de Arroz } \\
\text { Irrigado }\end{array}$ & 301.247 toneladas \\
\hline $\begin{array}{l}\text { Receita média anual de Arroz } \\
\text { Irrigado (2008-2011) }\end{array}$ & $\mathrm{R} \$ 176.099 .000,00$ \\
\hline $\begin{array}{l}\text { Custo médio anual de Produção de } \\
\text { Arroz Irrigado (2008-2011) }\end{array}$ & $\mathrm{R} \$ 164.014 .087,20$ \\
\hline $\begin{array}{l}\text { Vazão total de água utilizada para } \\
\text { irrigação na bacia (2008-2012) }\end{array}$ & $4.925 .295,25 \mathrm{~m}^{3} / \mathrm{dia}$ \\
\hline $\begin{array}{l}\text { Quantidade anual de água utilizada } \\
\text { para irrigação na bacia }\end{array}$ & $1.797 .732 .766,25 \mathrm{~m}^{3}$ \\
\hline
\end{tabular}

Fonte: IBGE (2014).

Para a determinação do volume de água consumido utilizou-se os dados de outorga obtidos junto ao NATURATINS, aonde se determinou que a vazão de $4.925 .295,25 \mathrm{~m}^{3} /$ dia se refere ao uso da irrigação na bacia do Formoso durante os anos de 2008-2012, com esse dado foi possível determinar a vazão anual de água consumida para a irrigaçáo no total de 1.797.732.766,25 $\mathrm{m}^{3}$ (Tabela 5).

A irrigação na bacia do rio Formoso foi utilizada por todas as culturas, temporárias e permanentes, na regiáo, tais como arroz, milho, cana-de-açúcar, feijão, sorgo, banana, abacaxi, melancia, mandioca e soja, porém como o arroz é a cultura de maior área de plantio na região e por não ser possível obter dados mais apurados, optou-se pela utilização de toda a vazão para irrigaçáo no cálculo da capacidade de pagamento unitária. 
Para o cálculo da capacidade de pagamento unitária do irrigante, $\left(\mathrm{CP}_{\mathrm{u}}\right)$, aplicou-se a equação 2 .

$$
\begin{aligned}
\mathrm{CPu} & =\mathrm{CPT} / \mathrm{V} \\
\mathrm{CPu} & =(\mathrm{R} \$ 12.084 .912,80) /\left(1.797 .732 .766,25 \mathrm{~m}^{3}\right) \\
\mathrm{CPu} & =\mathrm{R} \$ 0,0067 / \mathrm{m}^{3}
\end{aligned}
$$

58 Os produtores de arroz seriam capazes de pagar a quantia de $\mathrm{R} \$ 0,0067$ por metro cúbico de água. No entanto, caso o referido valor seja o preço a ser cobrado aos agricultores, ou seja, o preço unitário por metro cúbico, os produtores não teriam lucro nenhum em sua atividade, logo o preço de venda do arroz aumentaria e/ou inviabilizaria a produção na região.

\section{Análise de Viabilidade da Cobrança Pelo Uso da Água na bacia}

Para a determinação do preço unitário do metro cúbico de água na bacia, foram considerados os seguintes critérios:

$1^{\circ}$ critério: De acordo com a Política Nacional de Recursos Hídricos (Lei 9.433/97), "os recursos obtidos pela cobrança devem ser prioritariamente aplicados na bacia hidrográfica em que foram gerados" (BRASIL, 1997, Art. 22).

Aarrecadação deve ser utilizada no financiamento de estudos, programas, projetos e obras hidráulicas dentro da bacia do rio Formoso ou em áreas próximas que venham "melhorar" as condiçốes da bacia. Os recursos podem ser utilizados no custeio administrativo como, por exemplo, o comitê de bacia e sua agência.

$2^{\circ}$ critério: A cobrança só será realizada sobre os usuários de água que possuam a outorga de direito de uso da água.

Para que se possa determinar a quantia a ser cobrada de cada usuário é necessário que se meça o volume de água consumido por cada usuário, para isso existem mecanismos como os registros/medidores de água, porém há certo gasto para sua implantação, por isso para o presente estudo utilizou-se dos valores descritos na outorga de direito de uso da água.

$3^{\circ}$ critério: A quantia arrecadada só será aplicada em açóes que foram propostas no plano de bacia.

O plano de bacia, desenvolvido em 2007 pela corrigir Secretaria Estadual de Recursos Hídricos e Meio Ambiente, estabeleceu uma série de açôes e programas até o ano de 2035.

A Tabela 6 apresenta os custos de todas as açóes propostas no plano de bacia do rio Formoso. Esses custos foram separados por ano, de acordo com o prazo de implantaçáo de cada açáo.

Os valores variaram pouco, entre os 14-22 milhóes de reais, com exceção dos primeiros anos $(2008,2009$ e 2010), em que estava previsto "reformulação e complementação da infraestrutura hídrica de uso comum do projeto de irrigação rio formoso", vale ressaltar que essas obras não foram implementadas até o momento.

A média dos valores presentes na Tabela 6 , $\mathrm{R} \$ 26.326 .720,86$, serviu como a quantia a ser alcançada pela cobrança pelo uso da água e serviram de base para a elaboração dos cenários de financiamento para a aplicação dos recursos.

TABELA 6

Custos anuais necessários para a implantação das ações propostas pelo Plano de Bacia Hidrográfica do rio Formoso

\begin{tabular}{|c|c|c|c|}
\hline Ano & Valor (R\$) & Ano & Valor (R\$) \\
\hline 2008 & $153.986 .395,00$ & 2022 & $18.169 .637,78$ \\
\hline 2009 & $154.100 .335,71$ & 2023 & $20.156 .229,78$ \\
\hline 2010 & $3.765 .346,71$ & 2024 & $20.156 .229,78$ \\
\hline 2011 & $18.199 .268,95$ & 2025 & $22.496 .053,78$ \\
\hline 2012 & $17.613 .878,95$ & 2026 & $14.575 .755,57$ \\
\hline 2013 & $17.613 .878,95$ & 2027 & $14.575 .755,57$ \\
\hline 2014 & $17.613 .878,95$ & 2028 & $14.661 .963,07$ \\
\hline 2015 & $17.750 .378,95$ & 2029 & $14.661 .963,07$ \\
\hline 2016 & $17.613 .878,95$ & 2030 & $14.661 .963,07$ \\
\hline 2017 & $17.613 .878,95$ & 2031 & $14.733 .015,07$ \\
\hline 2018 & $17.952 .468,45$ & 2032 & $14.733 .015,07$ \\
\hline 2019 & $17.952 .468,45$ & 2033 & $14.733 .015,07$ \\
\hline 2020 & $17.952 .468,45$ & 2034 & $15.200 .062,07$ \\
\hline 2021 & $18.169 .637,78$ & 2035 & $15.735 .362,07$ \\
\hline \multicolumn{4}{|c|}{ Total 737.148.184,02 } \\
\hline \multicolumn{4}{|c|}{ Média 26.326.720,86 } \\
\hline
\end{tabular}

Fonte: Adaptado de RIBEIRO (2007).

\section{Formulação de Cenários e Determinação de Custos Unitários}

A partir dos custos para a implantação das açôes propostas no plano de bacia, foram elaborados cinco cenários, o primeiro com financiamento de $100 \%$, 
o segundo com $75 \%$, o terceiro com $50 \%$, o quarto com $25 \%$ e o quinto com $10 \%$ de cobertura financeira das açóes propostas no plano de bacia. A divisão dos custos anuais pelo volume de água consumida anualmente na bacia $\left(1.852 .479 .054,2 \mathrm{~m}^{3}\right)$ originou uma série de custos unitários conforme apresentado na Tabela 7.

TABELA 7

\section{Custos necessários para a implantação das ações propostas pelo Plano de Bacia Hidrográfica do rio Formoso}

\begin{tabular}{|l|c|}
\hline \multicolumn{2}{|l|}{$1^{0}$ Cenário de cobertura } \\
\hline Cobertura de $100 \%$ dos custos $(\mathrm{R} \$)$ & $26.326 .720,8600$ \\
\hline Custo unitário $\left(\mathrm{R} \$ / \mathrm{m}^{3}\right)$ & 0,0142 \\
\hline $2^{\circ}$ Cenário de cobertura & $19.745 .040,6450$ \\
\hline Cobertura de $75 \%$ dos custos $(\mathrm{R} \$)$ & 0,0107 \\
\hline Custo unitário $\left(\mathrm{R} \$ / \mathrm{m}^{3}\right)$ & $13.163 .360,4300$ \\
\hline $3^{\circ}$ Cenário de cobertura & 0,0071 \\
\hline Cobertura de $50 \%$ dos custos $(\mathrm{R} \$)$ & \\
\hline Custo unitário $\left(\mathrm{R} \$ / \mathrm{m}^{3}\right)$ & $6.581 .680,2150$ \\
\hline $4^{\circ}$ Cenário de cobertura & 0,0036 \\
\hline Cobertura de $25 \%$ dos custos $(\mathrm{R} \$)$ & \\
\hline Custo unitário $\left(\mathrm{R} \$ / \mathrm{m}^{3}\right)$ & $2.632 .672,0860$ \\
\hline $5^{\circ}$ Cenário de cobertura & 0,0014 \\
\hline Cobertura de $10 \%$ dos custos $(\mathrm{R} \$)$ \\
\hline Custo unitário $\left(\mathrm{R} \$ / \mathrm{m}^{3}\right)$ &
\end{tabular}

De acordo com a Tabela 7, para o primeiro cenário, em que todos os custos seriam pagos pelos usuários o custo unitário estaria muito acima da capacidade de pagamento dos agricultores ( $\mathrm{R} \$$ $\left.0,0067 / \mathrm{m}^{3}\right)$. Ao se requisitar a quantia média de $\mathrm{R} \$ 0,0142 / \mathrm{m}^{3}$, a produçáo agrícola irrigada, seria inviabilizada, uma vez que o valor cobrado seria muito superior à capacidade de pagamento máxima dos usuários.

No segundo cenário, com $75 \%$ dos custos pagos pelos usuários, o custo unitário seria de $\mathrm{R} \$ 0,0107 / \mathrm{m}^{3}$, ainda inviável por superar a capacidade de pagamento dos irrigantes.

Para o terceiro cenário se repete a mesma situação dos dois primeiros, não há capacidade de pagamento por parte dos usuários de irrigação.
O quarto e quinto cenários teriam o valor médio do metro cúbico de água em $\mathrm{R} \$ 0,0036$ e $\mathrm{R} \$ 0,0014$ respectivamente; Valores inferiores a capacidade de pagamento do usuário agrícola ( $\mathrm{R} \$ 0,0067)$; Nesses cenários os irrigantes estariam em condiçóes de internalizar os custos financeiros de uma cobrança pelo uso da água.

Outra perspectiva de se analisar o problema é considerando percentuais de comprometimento da capacidade de pagamento dos usuários. Para isso foram criadas propostas para a utilizaçáo de percentuais de sua capacidade de pagamento conforme demonstrado na Tabela 8.

TABELA 8

Cobertura da capacidade de pagamento do usuário agrícola a ser investida na cobrança

\begin{tabular}{|l|c|c|}
\hline $\begin{array}{c}\text { Cobertura da Capacidade } \\
\text { de Pagamento }\end{array}$ & $\begin{array}{c}\text { Valor } \\
\left(\mathbf{R} \$ / \mathbf{m}^{3}\right)\end{array}$ & $\begin{array}{c}\text { Cobertura dos } \\
\text { Custos do PBH } \\
\text { (\%) }\end{array}$ \\
\hline $\begin{array}{l}\text { 100\% da capacidade de } \\
\text { pagamento }\end{array}$ & 0,0067 & $47,2 \%$ \\
\hline $\begin{array}{l}75 \% \text { da capacidade de } \\
\text { pagamento }\end{array}$ & 0,0050 & $35,2 \%$ \\
\hline $\begin{array}{l}50 \% \text { da capacidade de } \\
\text { pagamento }\end{array}$ & 0,0034 & $23,9 \%$ \\
\hline $\begin{array}{l}25 \% \text { da capacidade de } \\
\text { pagamento }\end{array}$ & 0,0017 & $12,0 \%$ \\
\hline $\begin{array}{l}\text { 10\% da capacidade de } \\
\text { pagamento }\end{array}$ & 0,0007 & $4,9 \%$ \\
\hline
\end{tabular}

Ainda de acordo com a Tabela 8, ao se comprometer $100 \%$ da capacidade de pagamento dos usuários agrícolas, seria pago 47,2\% dos custos necessários para a implantação das açôes presentes no plano de bacia; Ao se utilizar 75\% da capacidade, $35,2 \%$ dos custos seriam cobertos; Com 50\%, 23,9\% dos custos são acobertados; Com $25 \%$, seriam pagos $12 \%$ dos custos; Com 10\% da capacidade de pagamento dos usuários agrícolas, 4,9\% dos custos das açóes propostas no plano seriam pagos.

Analisando conjuntamente os cenários com os diferentes percentuais da capacidade de pagamento dos produtores de arroz, pôde-se observar que a melhor situação, do ponto de vista financeiro, seria a aplicação do $4^{\circ}$ cenário, aonde $25 \%$ dos custos para implantaçáo dos projetos do plano de bacia viriam dos 
usuários, cobrando em média $\mathrm{R} \$ 0,0036 / \mathrm{m}^{3}$. Logo, algo próximo a $50 \%$ da capacidade de pagamento dos agricultores $(\mathrm{R} \$ 0,0034)$ seria utilizado na cobrança pelo uso da água e a metade restante seria o lucro pela atividade.

$\mathrm{Na}$ Tabela 9 são apresentados os valores de cobrança pelo uso da água praticados em algumas bacias e no Estado do Ceará, em que se verifica que o valor proposto de $50 \%$ da capacidade de pagamento dos irrigantes, para este estudo, não difere muito dos já praticados.

TABELA 9

Preço Público Unitário (PPU) em bacias hidrográficas que adotaram a cobrança pelo uso da água no Brasil

\begin{tabular}{|l|c|l|}
\hline \multicolumn{1}{|c|}{$\begin{array}{c}\text { Bacia } \\
\text { hidrográfica }\end{array}$} & $\begin{array}{c}\text { Preço Público } \\
\text { Unitário (R\$/ } \\
\left.\mathbf{m}^{3}\right)\end{array}$ & \multicolumn{1}{|c|}{ Especificação } \\
\hline Rio Paraíba do Sul & 0,03 & $\begin{array}{l}\text { Preço = Captação } \\
(0,02)+\text { Consumo } \\
(0,01)\end{array}$ \\
\hline $\begin{array}{l}\text { Rios Piracicaba, } \\
\text { Capivari e Jundiaí } \\
\text { (PCJ) }\end{array}$ & 0,03 & $\begin{array}{l}\text { Preço = Captação } \\
(0,02)+\text { Consumo } \\
(0,01)\end{array}$ \\
\hline Rio Doce & 0,021 & Captação \\
\hline Estado do Ceará & $0,00250,008$ & $\begin{array}{l}\text { Preço para } \\
\text { irrigantes, variável } \\
\text { em função do } \\
\text { consumo }\end{array}$ \\
\hline
\end{tabular}

Fonte: ANA (2015).

Ao se comparar o preço público unitário das bacias que já vêm utilizando a cobrança pelo uso da água no Brasil, é possível observar que os valores das bacias com cobrança são muito acima dos estimados para a bacia do rio Formoso; Isso ocorre porque os rios Paraíba do Sul, PCJ e Doce, estão localizados em áreas populosas, com grandes empresas usuárias de água, de alta capacidade de pagamento, e sofrem além do problema de escassez de água, com a má qualidade da água, por isso seus preços unitários variam entre $\mathrm{R} \$ 0,02 / \mathrm{m}^{3}$ e $\mathrm{R} \$ 0,03 / \mathrm{m}^{3}$, além disso, os principais usuários são indústrias e companhias de saneamento (Tabela 9).

O Estado do Ceará delimitou a faixa de $\mathrm{R} \$$ $0,0025-0,008 / \mathrm{m}^{3}$ para usuários agrícolas, valor próximo da capacidade de pagamento $\left(\mathrm{R} \$ 0,0067 / \mathrm{m}^{3}\right) \mathrm{e}$ dos valores apresentados no cenário mais propício - $4^{\circ}$ cenário $\left(\mathrm{R} \$ 0,0036 / \mathrm{m}^{3}\right)$. O Ceará sofre com grandes períodos de estiagem, com escassez de água em certas áreas do Estado, problemática similar à da bacia do rio Formoso; Por isso é pertinentea comparação e assimilação da experiência cearense ao se delimitar a proposta de cobrança pelo uso da água na bacia em estudo.

Todavia é importante destacar que os valores cobrados aos usuários de água nas regióes destacadas anteriormente é determinado por um conjunto entre o preço público unitário e coeficientes, por meio de equaçóes próprias criadas por seus comitês de bacia.

A adoção do preço unitário da bacia não deve ser fundamentada somente em estudos técnicos, como o presente trabalho, mas também em uma discussão entre os membros do comitê, abrangendo todos os usuários, para atingir seus objetivos principais, diminuição do desperdiço, adoção de técnicas menos demandantes de água e a arrecadação de recursos para a gestão da bacia hidrográfica, este estudo visa orientar e dar subsidiar o comitê de bacia em relação a implementação de um sistema de cobrança pelo uso da água.

\section{CONCLUSÕES}

A capacidade de pagamento dos usuários ainda é baixa, que pode demonstrar que a cobrança pelo uso da água nessa bacia onde a grande maioria dos usuários é irrigante, pode ser inviável em um primeiro momento.

Os recursos hídricos podem estar sendo usados de forma ineficiente, ou seja, se gasta uma grande quantidade de água para produzir um bem de baixo valor agregado.

Pode-se considerar que a bacia não pode sustentar uma área tão grande para plantio de arroz por inundação, e orientar outros tipos de plantio com menor consumo de água e maior valor agregado.

Os valores encontrados neste trabalho podem servir de referência para incentivar, pelo menos, a redução de perdas, cobrando um valor unitário menor para quem tivesse essas práticas, ou até cobrar menos para aqueles que migrarem para outro tipo de cultivo que consuma menos água por hectare do que $\mathrm{o}$ arroz irrigado.

Alerta-se que atualmente o consumo de água é intenso e que conflitos entre irrigantes já existem, sendo assim, o estudo de quaisquer instrumentos que possam incentivar o uso racional da água, é de suma importância para a bacia do rio Formoso. 


\section{Referências}

AGÜERO, P. H. Avaliação econômica dos recursos naturais. 1996. 224f. Tese (doutorado em Economia) - Universidade de São Paulo, 1996. AGÊNCIA NACIONAL DE ÁGUAS - ANA. Relatório 2009: Cobrança pelo Uso de Recursos Hídricos na Bacia Hidrográfica do Rio Paraíba do Sul. Brasília. 2010.

AGÊNCIA NACIONAL DE ÁGUAS - ANA. Índice de Cobrança. Disponível em: <http://www2.ana.gov.br/Paginas/servicos/cobrancaearrecadacao/cobrancaearrecadacao.asp>. Acesso em: 16 jan. 2015.

AQUINO, T. S. de A.; GOMES, C. C.; SOUZAFILHO, F. de A. de; SILVA, M. O. da. Impacto da Recuperação do Investimento em Infraestrutura Hídrica na Cobrança pelo Uso da Água. Revista Brasileira de Recursos Hidricos, v. 18, n. 1, p. 87-98, 2013.

BATE, R. N.; DUBOURG, W. R. A net-back analysis of irrigation water demand in east Anglia. Journal of Environmental Management, v. 49, p. 311-322, 1997.

BRASIL. Lei n. 9.433/97 - Política Nacional de Recursos Hídricos. Disponível em: <http://www.ana.gov.br /Institucional/Legislacao/leis/ lei9433.pdf>. Acesso em: 26 fev. 2015.

CAMPOS, R. T. Avaliação Sob Risco da Capacidade de Pagamento por Água Bruta de Produtores da Bacia do Jaguaribe (CE). Revista de Economia e Sociologia Rural, vol. 48, n 02, p. 357-380. 2010.

EMPRESA BRASILEIRA DE PESQUISA AGROPECUÁRIA - EMBRAPA. Cultivo do Arroz Irrigado no Estado do Tocantins. Disponível em: <http://sistemasdeproducao.cnptia.embrapa.br/FontesHTML/Arroz/ArrozlrrigadoTocantins>. Acesso em 10 dez. 2014.

Instituto Brasileiro de Geografia e Estatística - IBGE. Cidades. Disponível em: <http://www.ibge.gov.br>. Acesso em: 20 dez. 2014.

MENDONÇA, M. C. de. (Coord.). Plano Nacional dos Recursos Hídricos: Panorama e estado dos recursos hídricos do Brasil. Brasília, 351p. 2006.

NUNES JUNIOR, T. T.; MAGALHÃES JUNIOR, A. P. Perspectivas de Efetivação da Cobrança pelo Uso da Água no Brasil com Base no Caso da Porção Mineira da Bacia do Paraíba do Sul. Revista Brasileira de Recursos Hídricos, v. 14, n. 3, p. 17-26, 2009.

RIBEIRO, D. M. (Coord.). Plano de Bacia Hidrográfica do Rio Formoso: PBH Rio Formoso, no Estado do Tocantins. Palmas, 70p. 2007.

TEIXEIRA, J. C. T. Modelos de Gerenciamento de Recursos Hídricos: Análise e propostas de aperfeiçoamento do sistema do Ceará. 2003. 104f. Dissertação (Mestrado em Engenharia Hidráulica e Ambiental)- Universidade Federal do Ceará, 2003.

Luiz Norberto Lacerda Magalhães Filho Mestre em Engenharia Ambiental, Professor do IFTO campus Dianópolis, Engenharia Agronômica. E-mail: luiznorberto.filho@ifto.edu.br

Fernán Enrique Vergara Doutor em Tecnologia Ambiental e Recursos Hídricos,Professor Adjunto da UFT, Engenharia Ambiental. Email: vergara@ mail.uft.edu.br

Waldecy Rodrigues Phd em Economia, Professor Adjunto da UFT, Economia. Email: waldecy@terra.com.br. 
